\title{
Analysis of a teacher training process through the study of educational interaction
}

\author{
Chávez, Jorge ${ }^{a}$ and Jaramillo, Claudia ${ }^{a}$ \\ ${ }^{a}$ Unidad de Innovación Educativa, Universidad de Santiago de Chile, Chile.
}

\begin{abstract}
The purpose of the study is to describe and analyse the configuration of joint activity in a teacher's training process from a teaching and learning sociocultural perspective. From this theoretical perspective, formal learning is conceived as a mediated social construction process of meanings around learning content, and teaching as a process of planned, systematic and sustained support for that construction process. Taking this into consideration, an assessment course was video recorded to analyse the interaction between teachers and students undertaking this course. The findings describe how mechanisms of educational influence emerge in the form of assessment situations, specifically as instances of correction and feedback of the assessment results. The findings make it possible to visualise the way in which these training processes of university teachers are structured and the need to expand the research to the analysis of the interaction. This raises the need to consider the teaching of assessment as a complex process that acknowledges different situations that could be favouring self-regulation, beyond teaching a set of criteria, techniques and strategies to assess learning.
\end{abstract}

Keywords: Teacher training process; Sociocultural perspective; Mechanisms of educational influence; Interaction analysis 


\section{Introduction}

Recent changes in knowledge management and in the way of conceiving learning have brought the need to implement important teaching innovations, not only in higher education, but also at different educational levels and scenarios. In this sense, training programs in university teaching have acquired particular relevance at the time of carrying out teaching improvements in higher education (Postareff, Lindblom-Ylänne, \& Nevgi, 2007). In this context, most of the studies on training processes have been limited to aspects related to student satisfaction measurements, as well as to the teaching-learning approaches of teachers and students (Åkerlind, 2004; Prosser \& Trigwell, 2001). This has led to a series of questions related to the need for in-depth qualitative studies associated with activity that takes place in a process of university teacher training (Stes et al. 2013). In this context, it is necessary to complement the existing research with referential frameworks that consider the analysis of educational activity, oriented at understanding the structure of the activity carried out by teachers and students participating in that process (Mercer \& Coll 1994; Mercer, 2010).

The present study aims to describe and analyse the configuration of joint activity that takes place in teachers' training processes, while placing emphasis on educational influence mechanisms (EIM). This study also seeks to determine how these processes facilitate changes in university teaching practice.

\section{The study of educational practice: a theoretical model for analysis}

From a constructivist perspective of sociocultural orientation, formal learning is conceived as a social construction process mediated by meanings around the content of learning, where teaching is a process of planned, systematic and sustained help in support of that construction process (Coll et al. 2008). In this relation, this research focuses on the structure taken by the educational support provided by the teachers and the students themselves while they interact in a teaching and learning situation. Understanding"educational support" as the support given by the teacher to the students in response to their requirements and needs during the teaching and learning process (Coll \& Rochera, 2000).

Most of the work in this perspective focuses on complete instructional processes because it enables to comprehend the complete unit or the temporal dimension of the teaching and learning process, since the construction of knowledge requires time for its elaboration (Coll et al. 2008; Mauri \& Barberà, 2007; Sánchez \& Rosales, 2005; Rosales, Iturra, Sánchez \& De Sixte, 2006; Scardamalia \& Bereiter 2006; Schwarz, Dreyfus, \& Herschkowitz, 2009). Once the analysis unit -a complete didactic sequence (DS) - has been chosen, it is necessary to identify the interactivity episodes or segments that compose it, which can be described as a series of performances shared by all the participants (Coll \& Rochera, 2000; Cubero, 2005). 
For the purpose of identifying the segments, two conditions must be fulfilled. First, the following questions must be answered: who can do what, with whom can it be done, and how can it be done. In the second level of analysis, and as a consequence of the first, there is the discursive activity carried out by the participants, which is focused on the analysis of the activity's semiotic content. In this level the objective is to identify how the meaning of the activity is constructed and reconstructed through the interpretation of the discourses of the participants, leading to analytical categories that arise from it.

Some studies show by means of maps how the activity is organized (Coll \& Rochera, 2000). These maps, called "interactivity maps", allow visualizing better the way participation is structured from the observation of the configuration (duration and evolution of the segments in the didactic sequence) of the interactivity segments (Coll et al. 2008). Another element that must be considered is that EIM are enacted in the sphere of interactivity, which is defined as the «accumulation of the actions of teachers and students around a given task or content», giving rise to different forms of organization of joint activity (Coll \& Sánchez, 2008). There are numerous research reports that operate on this concept of interactivity (Harris \& Williams, 2011; Rochera \& Naranjo, 2007; Wilson, Andrew, \& Below, 2006).

In synthesis, the application of this framework with its different levels of analysis, allows for a theoretical and practical basis for the study of activity specifically the activity of teaching and learning that takes place in university training scenarios (Chávez \& Jaramillo, 2014).

\section{Method}

With the purpose of understanding how the joint activity is configured in a process of training in university teaching, a qualitative approach was used. The process of data analysis considered a complete video recorded didactic sequence (DS), consisting of four whole sessions of an "Assessment of Learning" course for a Diploma in university teaching in a Chilean university. In total, 9 hours and 46 minutes of video recordings were collected. The topics dealt with in the sessions are related to theoretical and practical aspects of the assessment of learning in higher education. The participants in this study were 15 teachers from different academic units. Once the DS had been video recorded, it was transcribed and then analysed based on criteria derived from the analysis framework, which implied the identification of interactivity segments and the predominant actions present in the previously delimited segments, including their configuration and their relation with EIM.

\section{Findings}

Considering the total amount of data collected, eight segments have been identified. Those segments have initially been called starting, content, instruction, oral presentation, task, 
assessment guideline presentation, group work, and closing segment. The temporal evolution and the articulation of the segments are what constitute the structure of the joint activity and allow a panoramic view of the interaction that takes place throughout the instructional process, which can be represented graphically through the interactivity map (Fig. 1).

In the starting segments a rapid review of the contents and activities that have taken place in previous sessions is made and the new contents and/or activities that will be developed are presented. The closing segment responds to different moments of the joint activity and not necessarily to the end of a session. The contents segments correspond to $20.8 \%$ of the total of the DS, and they are associated with the management of the delivery of information related to the conceptual foundations of the course.The instruction segment corresponds to $3.4 \%$ of the DS and contains directions with respect to the organization of the work to be developed in the following sessions. Similarly, in the task segment, which corresponds to $1.3 \%$ of the DS and appears in the first and second sessions, the teachers and the teacher trainer carry out preparatory activities related to the development of the academic task.

The assessment guideline presentation segment corresponds to only $1.5 \%$ of the DS and it is the instance in which the teacher trainer hands out the instrument that will be used to evaluate activities developed in the third and fourth sessions. Finally, the group work and oral presentation segments are the longest in the DS and are considered the most important, mainly because it is in these segments that educational aids arise, linked specifically with the assessment situations. Linking the segments and the predominant and non-predominant actions allows for identifying how and when the educational supports are implemented. In this case, those aids are found mainly in the group work and oral presentation segments.

Previous work along this field (Coll and Rochera 2000; Rochera and Naranjo 2007) considers the assessment situations as a set of moments that are not limited only to the assessment instance itself, but also consider aspects such as instances of preparation of the activity that will be evaluated and following the assessment itself, e.g., the instances of correcting, returning and profiting from the results of the assessment. Ultimately, the object of analysis corresponds to the patterns of activity located in the group work and oral presentation segments, which are related to instances in which the teacher trainer, on the one hand, rectifies and comments on the work done by the teachers in the workshops in situ and, on the other hand, gives feedback to the participants in situ and the products that they have developed. 


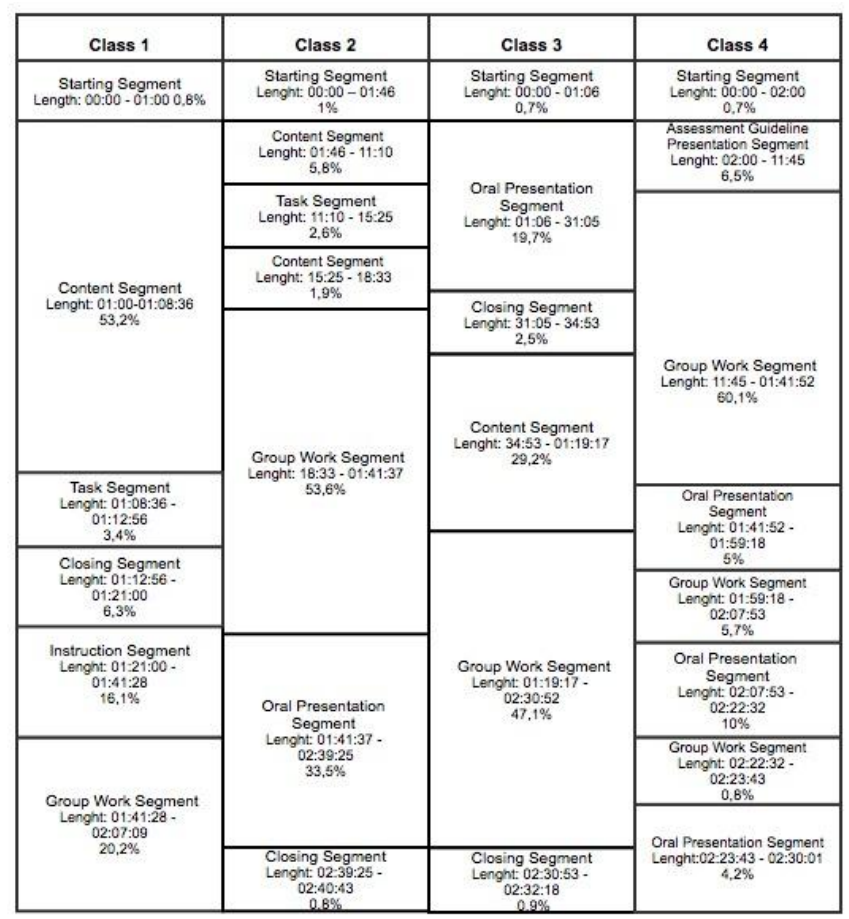

Fig. 1. Interactivity map

It is in the group work and oral presentation segments that these actions, or assessment situations, are more visible as they occur more frequently, in particular towards the end of the DS. In the work group segments, the predominant actions are related to correction instances, which take place mostly after the teachers have finished the tasks assigned for each session. In the following fragment it is shown how the teacher comments the work developed by the teachers (the making of a rubric).

Transcript Class 3 "Non-traditional assessment instruments: The rubric as an authentic assessment instrument of the learning"( second block, group workshop).

Teacher trainer: I see this (rubric), as a student, and I say "I do almost nothing and I still pass".

Teacher:

We have the perception that when applying this, regardless of the different scores of the items, we are requiring $60 \%$.

Teacher trainer: $\quad$ I believe that it is less, we pass doing almost nothing.

Teacher:

The worst grade that I've given is 4.8 .

Teacher trainer: We cannot construct a scale like this. It is incorrect. By definition we cannot construct something dichotomous for something that is plural. 
This example corresponds to the rubric construction workshop that takes place between the third and fourth sessions of the DS, supported with instructions projected on the board. In it, the teacher trainer corrects the instrument of each of the work groups.

In the oral presentation segments, the teachers present the results of the work done in the workshops. The oral presentation segments occur at the end of the sessions, where each group chooses a representative who shows the product of the work done. During the presentations of the groups the trainer participates asking questions and giving feedback on the results of the work done by the teachers. An example of this is the following fragment, which shows the comments of the trainer after the presentation of the results of the work done in one of the workshops (preparation of comparison guideline):

Transcript Class 4 "Non-traditional assessment instruments: the rubric as an authentic assessment instrument of the learnings" (first block, continuation of group workshop Class 3).

Teacher trainer: Before going on with the following stage, how do you find the definition of the activity? What aspects stand out? What aspects can be improved?

Teacher: The "what for" is missing, like in last week's definition, it is necessary to know "what I'm doing this for".

Teacher trainer: What's important here is that the definition should be conceptual and operational at the same time. To define what the objective is. In this case, the objective must be defined, it must be mentioned that it is a research project and what it is about. For example, it is stated that the project should have an introduction but it is not explained, there is no quality criterion indicating how that introduction should be.

In this example the teacher trainer provides feedback on the work done by one of the groups. Here, not only something is clarified but also the work done is used as an example to reinforce a concept, in this case the concept of activity that the comparison guideline must contain. In short, the predominant actions that constitute EIM in this DS take the form of correction and feedback of the work done by the teachers as support is given every time the teachers perform assessment tasks throughout the DS.

The feedback referenced here it's related to the concept of continuous assessment. Continuous assessment is a formative process in which teachers and students work together in order to improve learning and collaborative construction of knowledge (Mauri, Ginesta, \& Rochera, 2014). According to Shute (2008, 154) formative feedback is defined as "information communicated to the learner that is intended to modify his or her thinking or behaviour for the purpose of improving learning". As pointed out by Shute, the premise here is that good feedback, if delivered correctly, may greatly improve learning outcomes and processes.

\section{Discussion}

In the analysed DS, EIM are materialized in the group work and oral presentation segments, because the adjustment of the educational support appears with greater regularity and 
intensity in those. The former, characterised by actions performed by the teacher trainer that aim to correct the work developed by the group -in situ-, and the latter by actions that provide feedback as a function of the assessment tasks. Both instances can be interpreted in terms of the transfer of control and the joint construction of meanings. They are present in almost all the sessions, but they are particularly more visible at the end of the DS as part of assessment situations. However, neither the transfer of control nor the shared construction of meanings take place linearly or progressively, as corroborated in previous work (Mauri and Barberà 2007).

Work that pays special attention to the assessment situations (Rochera and Naranjo 2007) identifies different moments or episodes that constitute an assessment situation, which allows for the assessment of the actions associated with correction and feedback in a context in which the central content of learning is the assessment. Furthermore, the assessment situations favour offering pedagogical supports needed to promote the process of attributing an essential sense to the learning because it is in these instances that the trainer assesses, corrects and works on these results, thus showing the importance of relating EIM with the assessment situations or the support devices that appear in this DS.

In the same line of thinking it is important to highlight the role played by the feedback. In this specific case, the teachers in training are learning to evaluate and at the same time are being evaluated under the same criteria taught in the course. The premise here is that as long as the teachers are given feedback on their own performance, the will improve their knowledge an also will better their pedagogical practice concerning the relevance of feedback in assessment situations.

However, it should be noted that there is consensus with respect to the need to expand the research toward educational practices as a methodological alternative with the purpose of facilitating the understanding of knowledge construction processes that occur in different educational levels and scenarios. From this standpoint, a relevant contribution is the importance given to the analysis of the activity and the discourse, putting special emphasis on the activity itself. In this context, it should be noted that the methodological elements presented in this study highlight the need for a micro and molar analysis of educational activity in different levels and scenarios.

\section{References}

Åkerlind, G. (2004). A New Dimension to Understanding University Teaching. Teaching in Higher Education, 9(3), 363-75. doi: 10.1080/1356251042000216679.

Barron, B. (2006). Interest and self-sustained learning as catalysts of development: A learning ecology perspective. Human Development, 49(4), 193-224.

Chávez, J., \& Jaramillo, C. (2014). El estudio de las prácticas educativas y su relevancia para el análisis de procesos de formación en docencia universitaria. Calidad en la educación, 41, 161-76. doi: $10.4067 /$ S0718-45652014000200007. 
Coll, C., \& Onrubia, J. (1999). Discusión entre alumnos e influencia educativa del profesor. Didáctica de la Lengua y la Literatura, 20, 19-37.

Coll, C., Onrubia, J. \& Mauri, T. (2008). Ayudar a aprender en contextos educativos: el ejercicio de la influencia educativa y el análisis de la enseñanza. Revista de educación, 346, 33-70.

Coll, C., \& Rochera, M. J. (2000). Actividad conjunta y traspaso del control en tres secuencias didácticas sobre los primeros números de la serie natural. Infancia y Aprendizaje, 23(4), 109-130. doi:10.1174/021037000760087801

Coll, C., \& Sánchez, E. (2008). El análisis de la interacción alumno-profesor: líneas de investigación. Revista de educación, 346, 15-32.

Cole, M., \& Engeström, Y. (2001). Enfoque histórico-cultural de la cognición distribuida. In G. Salomon (Ed.), Cogniciones distribuidas: Consideraciones psicológicas y educativas (pp. 23-74). Buenos Aires: Amorrortu Editores.

Colomina, R., Onrubia, J. \& Rochera, M. J. (2001). Interactividad, mecanismos de influencia educativa y construcción del conocimiento en el aula. In C. Coll, J. Palacios \& A. Marchesi (Eds.), Desarrollo psicológico y educación (pp. 437-460). Spain: Alianza Editorial.

Edwards, D., \& Mercer, N. (1987). Common Knowledge: The development of understanding in the classroom. London: Methuen.

Engeström, Y., Engeström, R., \& Kärkkäinen, M. (1995). Polycontextuality and boundary crossing in expert cognition: Learning and problem solving in complex work activities. Learning and Instruction, 5(4), 319-336. doi: 10.1016/0959-4752(95)00021-6

Harris, D. \& Williams, J. (2011). The association of classroom interactions, year group and social class. British Educational Research Journal, 38(3), 373-397. doi: 10.1080/01411926.2010.548547

Hoban, G. F. (2002). Teacher learning for educational change: A systems thinking approach. Buckingham: Open University Press.

Lave, J. (1996). Teaching, as learning, in practice. Mind, Culture, and Activity, 3(3), 149-164. doi: $10.1207 / \mathrm{s} 15327884 \mathrm{mca} 0303 \_2$

Mauri, T. \& Barberà, E. (2007). Regulación de la construcción del conocimiento en el aula mediante la comunicación de los resultados de aprendizaje a los alumnos. Journal for the Study of Education and Development, 30, 483-497. doi: 10.1174/021037007782334364

Mauri, T., Ginesta, A. \& Rochera, M. J. (2014). The use of feedback systems to improve collaborative text writing: a proposal for the higher education context. Innovations in Education and Teaching International, 1-13. doi:10.1080/14703297.2014.961503.

Mercer, N. (2004). Sociocultural discourse analysis: analysing classroom talk as a social mode of thinking. Journal of Applied Linguistics, 1, 137-168.

Mercer, N. (2010). The analysis of classroom talk: methods and methodologies. British Journal of Educational Psychology, 80, 1-14. doi: 10.1348/000709909X479853

Mercer, N. \& Coll, C. (1994). Teaching, Learning and Interaction. Fundación Infancia y Aprendizaje.

Postareff, L., Lindblom-Ylänne, S., \& Nevgi, A. (2007). A Follow-up Study of the Effect of Pedagogical Training on Teaching in Higher Education. Higher Education, 56(1), 29-43. doi: 10.1007/s10734-007-9087-z.

Prosser, M., \& Trigwell, K. (2001). Understanding Learning and Teaching: The Experience in Higher Education. Buckingham: Open University Press

Rochera, M. J., \& Naranjo, M. (2007). Fostering self-regulated learning in an assessment situation. Electronic Journal of Research in Educational Psychology, 5(3), 805-924. 
Rosales, J., Iturra, C., Sánchez, E., \& De Sixte, R. 2006. El análisis de la práctica educativa. Un estudio de la interacción profesor-alumnos a partir de dos sistemas de análisis diferentes. Infancia y Aprendizaje, 29(1), 65-90. doi: 10.1174/021037006775380920

Sánchez, E., \& Rosales, J. (2005). La práctica educativa. Una revisión a partir del estudio de la interacción profesor-alumnos en el aula. Cultura y Educación, 17(2), 147-173. doi: $10.1174 / 1135640054192865$

Shute, V. (2008). Focus on formative feedback. Review of Educational Research, 78(1), 153-189. doi: $10.3102 / 0034654307313795$.

Wilson, L., Andrew, C., \& Below, J. (2006). A comparison of teacher/pupil interaction within mathematics lessons in St Petersburg, Russia and the North-East of England. British Educational Research Journal, 32(3), 411-441. doi:10.1080/01411920600635429 